\title{
LYNX MOBILE MAPPER FOR SURVEYING CITY CENTERS AND HIGHWAYS
}

\author{
D. Conforti ${ }^{a}$, F. Zampa ${ }^{b}$ \\ a Dario Conforti, Optech Incorporated - darioc@optech.ca \\ b Federica Zampa, Sineco SpA - federica.zampa@sineco.co.it
}

Commission V, WG 4

KEY WORDS: Laser Scanner, LiDAR, Mobile Mapper, Lynx

\begin{abstract}
In the last two years the Lynx Mobile Mapper has become the new lidar solution developed for surveying large areas that are impractical with static lidar sensors and require an accuracy and resolution that exceed airborne technologies. The system allows the scanning at a speed up to $100 \mathrm{~km} / \mathrm{h}$, obtaining accuracy better than $5 \mathrm{~cm}$ with an up to $7 \mathrm{~mm}$ resolution. Therefore, this solution proves to be an excellent tool for surveying city centers, highways, railways, thanks also to a very fast, safe and accurate data collection. This paper will present two applications:

1- The survey of the entire ancient city center of Brescia (Italy) with it medieval castle, the narrows streets and the main squares. It also has been run a test to survey with the Lynx the tunnel that go underneath the castle and compare the result with a static laser scanner survey,

2- The survey of the Calatrava Bridge on the A1 highway. The central bridge, which crosses over the high-speed rail line and the A1 motorway is composed as a single symmetrical arch, placed longitudinally, which rises to a height of $46 \mathrm{~m}$. During the survey the two A1 motorway carriageways have been scanned and the upper part of the bridge for a complete 3D model of this structure.
\end{abstract}

\section{INTRODUCTION}

Since 2006 Sineco has started collaboration with Optech for the development of a new mobile mapping system. The first prototype, delivered at the beginning of 2007, was based on a platform combining together two ILRIS 3D static laser scanners (scanning horizontal and vertical) and a position and orientation system (Applanix POS LV 420), which consists in an inertial measurement unit (IMU), two dual-frequency GPSs receivers and a distance measurement indicator. This was the proof-of-concept that paved the way for the development of the new Lynx Mobile Mapper, a fully integrated system with a totally new concept $360^{\circ}$ laser sensors which allows to survey large areas at a very high speed (up to $100 \mathrm{~km} /$ hour), obtaining a $360^{\circ}$ high resolution (up to $1 \mathrm{~cm}$ ) point cloud.

This paper presents the surveys of three different subjects: The survey of the entire ancient city center of Brescia and the survey of the Calatrava Bridge on the A1 highway

\section{THE TECHNOLOGY}

The Lynx Mobile Mapper survey solution is designed for collecting engineering/survey grade lidar data over large areas that are impractical with static lidar sensors but require an accuracy and resolution that exceed airborne technologies. With system accuracy better than $5 \mathrm{~cm}$, a measurement rate up to 1 million points per second, $360^{\circ}$ field of view and a resolution of up to $1 \mathrm{~cm}$, the Lynx offers unprecedented 3D details surveying at speeds up to $100 \mathrm{~km} / \mathrm{hr}$.

The Sineco's system has a Lynx rigidly mounted platform above the car (Figure 1) that hosts the two orientated lidar sensors as well as platform for the system IMU and GPS antennae. A rigid design for the entire mount structure ensures that alignment and accuracy between the sensors and the navigational equipment is maintained.

The configuration with two sensors help to survey the entire survey area, having the opportunity to minimize the shadowing due from the objects present along the way and to optimize the field of view having a full coverage.

The Applanix POS/LV 420 is used to correct the orientation and position of the two sensors generating automatically a complete geo-referenced point cloud. The POS contains three accelerometers and three gyroscopes which measure the acceleration and angular velocity necessary for computing all aspects of the vehicle motion: position, speed, acceleration, orientation and rotation.

Two dual-frequency (L1/L2) GPS receivers track and record the vehicle path. Differential GPS processing is used to correct and refine the geo-referenced data. 


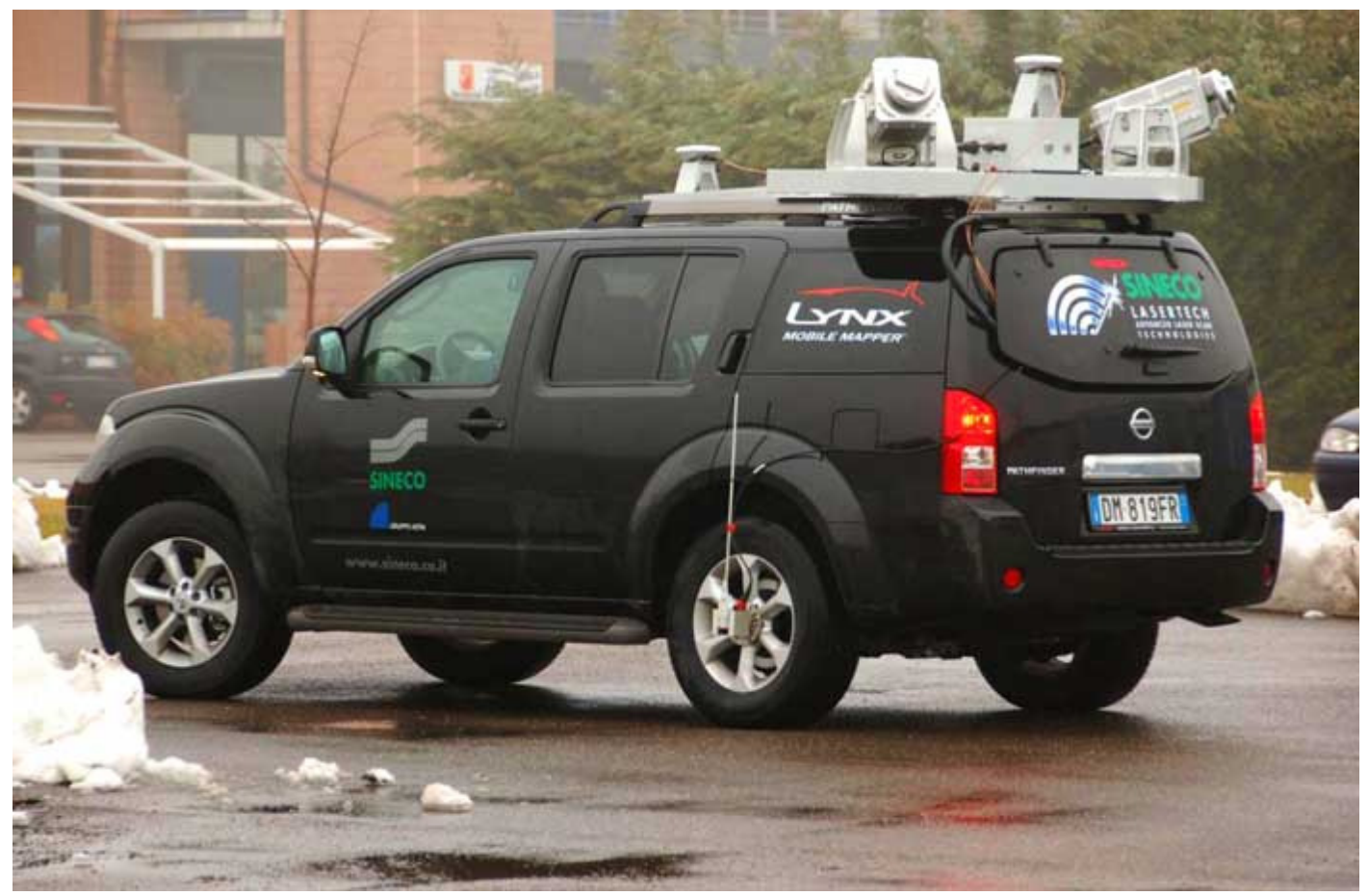

Figure 1 - Van with all the system components

\section{SYSTEM INTEGRATION}

The connectivity between the lidar sensors and POS is limited to synchronizing the clocks between the instruments. This operation is executed by setting up a GPS PPS connection that let the laser to timestamp events with its local clock. In the same time a GPS NEMEA string is required to indicate the precise GPS time of the previous PPS event. The lidar sensors will then use this time to establish the offset between their local clocks and GPS time.

POS has its own orientation and position above the platform and it is important to know the exact orientation and location of both lidar sensors regard to the POS. For this reason the Lynx has to be calibrated once mounted on the vehicle.

\section{WORKFLOW}

The survey starts in the office with a "mission planning" where the survey parameters (trajectory, the speed etc.) are stated according to the final result aimed. After the field work the results consist in two different files: a range file generated from both the Lidar sensors and a dataset generated from the POS. Through the POSpack software the SBET (Smooth Best Estimated Trajectory) is generated and it represents the best fitting of the trajectory made by the vehicle.

The SBET is used for orientating and positioning the lidar sensor data. The final survey result, which is a geo-referenced point cloud, is obtained inputting the SBET file and the raw lidar data into the Optech Dash Map software.

\section{THE BRESCIA CITY CENTER SURVEY}

This work has been carried out on December 2009 surveying a total of $30 \mathrm{~km}$ of the entire ancient city center of Brescia (Italy) with it medieval castle, the narrows streets and the main squares. It also has been run a test to survey with the Lynx the tunnel that go underneath the castle and compare the results with a static laser scanner survey.

The aim of the project was to obtain the faithful model reconstruction of some main buildings in the historical area for having a complete archive (Figure 2).

Due to the narrow streets and the tall buildings the GPS can run sometimes outrange and the POS can correct the location though the DMI (Distance Measurement Indicator): The DMI is a wheel-mounted rotary shaft encoder that measure precise linear distance traveled. These measurements give the POS LV a very accurate velocity measurement that helps constrain drift errors during GPS outrages. 


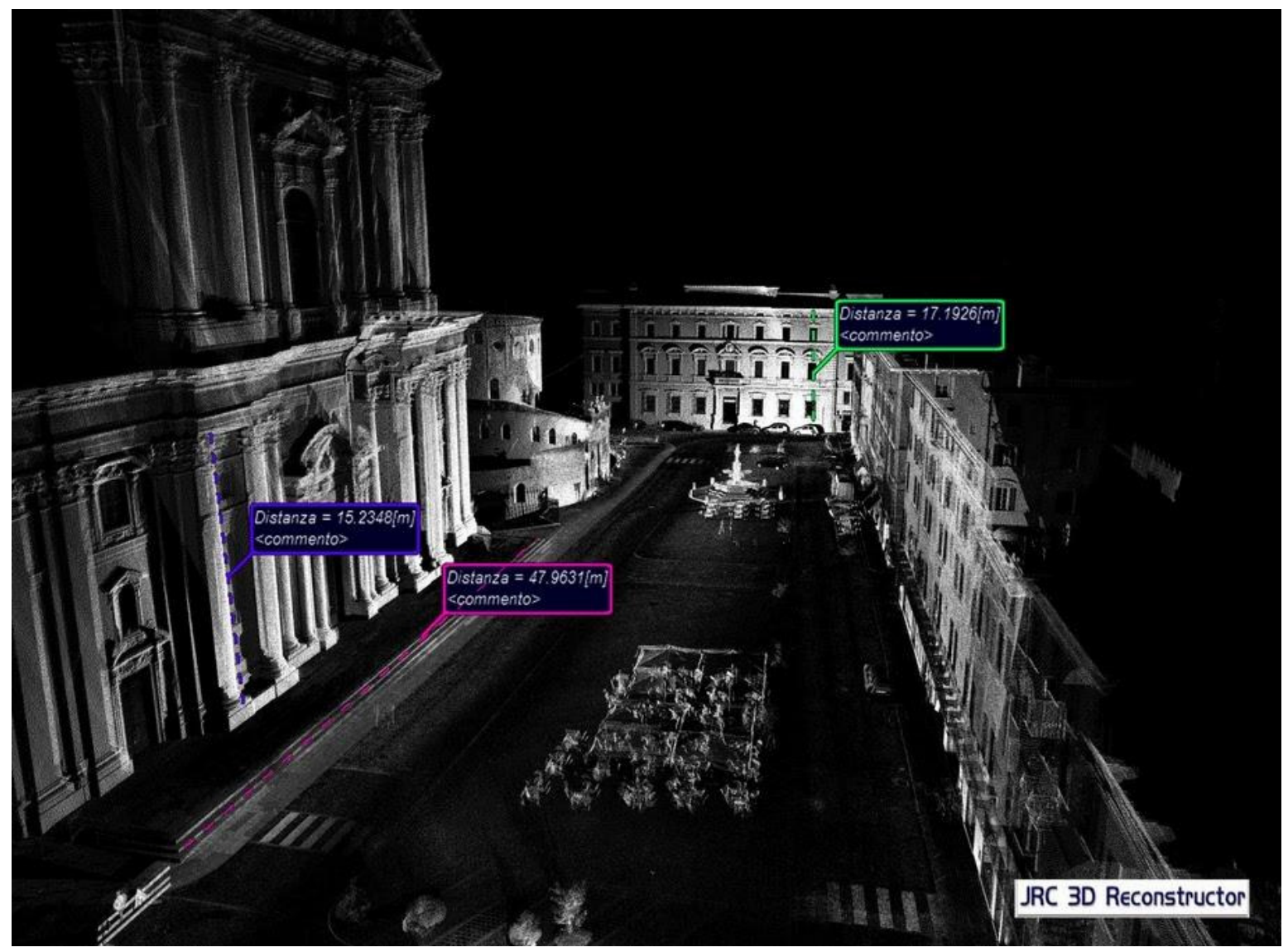

Figure 2 - Brescia City centre point cloud

Due to the traffic the entire area has been scanned at an average speed of $25 \mathrm{~km} / \mathrm{h}$, collecting data with a spot spacing of about $4 \mathrm{~cm}$. In 20 minutes has been collected 5 blocks for a total of 144 million points.

All the pre-processing has been carried out using a single Base Station placed around the area and the processing has been done with Reconstructor software.

\section{THE A1 HIGHWAY AND CALATRAVA BRIDGE SURVEY}

This work has been carried out on November 2009 surveying a total of $80 \mathrm{~km}$ of the A1 Highway close to the Reggio Emilia exit, composed by three lanes plus the shoulder one. The aim of the project was the scan of the new Calatrava Bridge (Figure 3) and obtaining the CAD reconstruction of the existing main features (pavement, structures, slopes, road signs, poles, etc.), as new works are planned to be done on this highway, such as the construction of a new link-up motorway and the preservation of existing parts. The central bridge, which crosses over the high-speed rail line and the A1 motorway is composed as a single symmetrical arch, placed longitudinally, which rises to a height of $46 \mathrm{~m}$. During the survey the two A1 motorway carriageways have been scanned and the upper part of the bridge for a complete 3D model of this structure. The resulting point cloud is an efficient archiving of the "as built" situation for future reference.

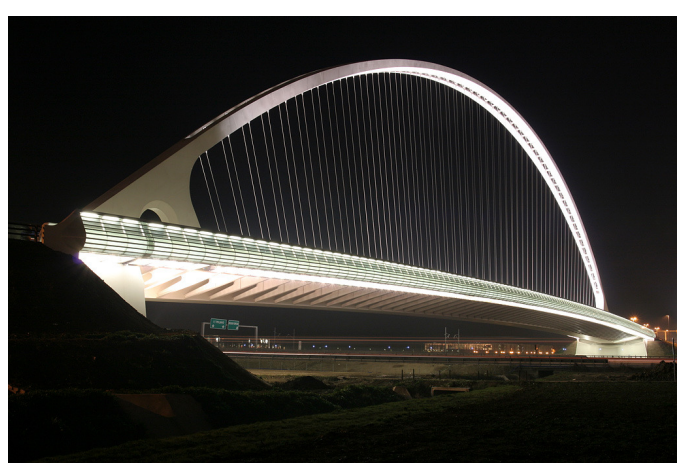

Figure 3 - Calatrava Bridge

This part of the highway has been surveyed in only 30 minutes at an average speed of $60 \mathrm{Km} / \mathrm{h}$ acquiring 600 million points. The point cloud was generated in WGS84 with a final average spot spacing of $10 \mathrm{~cm}$ (Figure 4). 


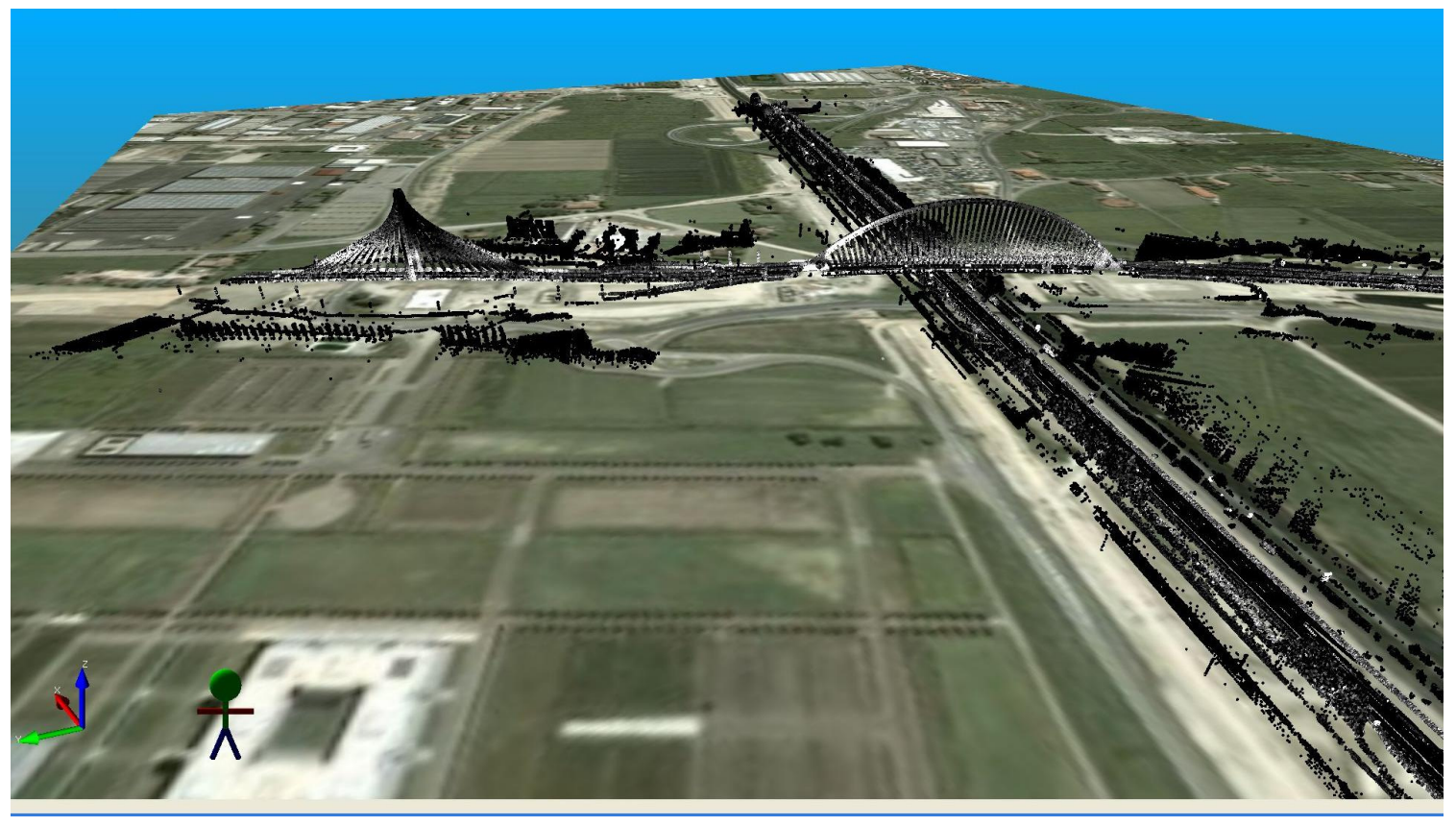

Figure 4 - Point cloud of Calatrava Bridge

In order to increase the final point cloud accuracy a base stations and some ground control points have been located along the entire survey area. The final point cloud accuracy was within $2 \mathrm{~cm}$. In order to get all the results needed, different software has been used for data processing such as Reconstructor and PolyWorks.

\section{CONCLUSIONS}

These applications presented demonstrated how this new Lynx mobile mapping technology can perform surveying easily at an impressive speed without blocking and interfering with the traffic in a total safe environment.

The geo-referenced point cloud obtained has a very high resolution and represents a complete database of information that anyone can examine anytime. The high density of the point cloud allows to easily identifying features and objects such as structures, slopes, road signs, poles, buildings features, etc. Definitely the Lynx has changed the topographical laser scanner survey scenario; suffice it to say that for scanning $80 \mathrm{~km}$ of highway with a traditional ground base laser scanner and total station on 2007, 120 working days have been needed only for the field survey comparing with the three hours of the Lynx for scanning.

\section{Biography of the Authors}

Federica Zampa graduated with high marks in Environmental Engineering. She worked as a GIS and
IT Specialist in two high profile Research Centers, ITC - Irst Centre for Scientific and Technologic Research and CEH Edinburgh. Since early 2006 she has joined Sineco S.p.A. and works as Project Manager in the Research and New Technologies Development area, keeping special attention to the new laser mobile system development.

Dario Conforti has a degree in Urban Architecture from the Polytechnic University of Milan. His studies included both cartography and photogrammetry. With almost ten years experience in laser-scanner technology, he joined Optech Inc in early 2006 as a world wide technical support. He also has extensive experience in GPS, bathymetry, airborne LiDAR and photogrammetry. 